\title{
Julie Boch, Les dieux désenchantés. La fable dans la pensée française de Huet à Voltaire (1680-1760)
}

\section{Stefania Bartoccioni}

\section{(2) OpenEdition}

10 Journals

\section{Édition électronique}

URL : https://journals.openedition.org/studifrancesi/40682

DOI : 10.4000/studifrancesi.40682

ISSN : 2421-5856

Éditeur

Rosenberg \& Sellier

\section{Édition imprimée}

Date de publication : 1 juillet 2004

Pagination : 189-191

ISSN : 0039-2944

\section{Référence électronique}

Stefania Bartoccioni, « Julie Boch, Les dieux désenchantés. La fable dans la pensée française de Huet à Voltaire (1680-1760) », Studi Francesi [En ligne], 142 (XLVIII | I) | 2004, mis en ligne le 30 novembre 2015, consulté le 09 septembre 2021. URL : http://journals.openedition.org/studifrancesi/40682; DOI : https://doi.org/10.4000/studifrancesi.40682

Ce document a été généré automatiquement le 9 septembre 2021.

\section{(c) $(1) \odot$}

Studi Francesi è distribuita con Licenza Creative Commons Attribuzione - Non commerciale - Non opere derivate 4.0 Internazionale. 


\title{
Julie Boch, Les dieux désenchantés. La fable dans la pensée française de Huet à Voltaire (1680-1760)
}

\author{
Stefania Bartoccioni
}

\section{RÉFÉRENCE}

JULIE восн, Les dieux désenchantés. La fable dans la pensée française de Huet à Voltaire

(1680-1760), Paris, Honoré Champion, 2002, pp. 577.

1 Stimulée par la constatation du grand nombre d'érudits qui, en France, pendant la période comprise entre 1680 et 1760 , concentrèrent leur attention sur la fable (pour la défendre ou pour la contester) et par le poids que les discussions sur les cultes païens eurent à l'intérieur des querelles des Anciens et des Modernes, des catholiques et des protestants, des chrétiens et des sceptiques, Julie Boch se propose dans ce volume d'étudier «la place de la fable dans la pensée française du début du siècle des Lumières [et] le regard que cette époque porta sur les légendes et le culte païens» (p. 14). Son but est d'opérer une lecture, une mythologie de la fable, à savoir une «réflexion de type rationnel» sur «un système interprétatif stabilisé et généralisé» (Starobinski), pour en mettre en évidence la valeur religieuse, historique, métaphysique, morale et littéraire. Il en résulte une analyse fine et détaillée menée à travers cinq parties, chacune caractérisée par une épigraphe emblématique et précédée d'une courte introduction qui explique le passage d'un nucleus thématique à l'autre.

2 Les nombreux points de vue, conceptions, méthodes et théorisations, plus ou moins systématiques et/ou systématisés, exigent une définition et une schématisation, synthétisée par l'auteur en cinq tendances fondamentales (relevées sur la base de critères religieux, historiques ou esthétiques): dans la fable on peut voir la copie dégradée de la révélation judéo-chrétienne (thèse diffusionniste ou du plagiat), le résultat d'un ensemble d'éléments de la civilisation de la côte méditerranéenne, 
l'altération de l'histoire ancienne, le moyen d'expliquer les phénomènes naturels et enfin un pur produit poétique (p. 14). Dans ce voyage à travers les écrits hétérogènes des penseurs qui contribuèrent au procès de «laïcisation progressive de la fable» (expression sur laquelle Julie Boch insiste plusieurs fois), une place considérable est réservée à Huet, à Bayle (toute la quatrième partie, pp. 305-418) et à Fontenelle.

Dans la première partie («Le comparatisme biblique ou le triomphe de la lecture allégorique») l'Auteur rappelle que toutes les théories modernes sur la mythologie païenne et chrétienne existent dès l'Antiquité classique et que les lectures allégoriques (et anti-allégoriques) furent très communes parmi les exégètes païens et les Pères de l'Église. D'où l'excursus rapide qui retrace les positions assumées par Pythagore, Héraclite, Anaxagore, Diogène d'Apollonie, Démocrite, l'école cynique, Platon, Aristote. Julie Boch souligne l'importance de l'allégorisme stoïcien (d'où l'allégorisme réaliste, ou mieux évhémériste, d'Evhémère, de Diodore et de Strabon et l'allégorisme extravagant à base pseudo-philologique d'Apollodore). Elle passe ensuite à présenter le courant intermédiaire qui résulta de la diversification de l'allégorisme hellénique en allégorisme juif et allégorisme chrétien. Avec Origène, Celse, Julien, Porphyre, la thèse $\mathrm{du}$ plagiat et celle de la condescendance convergent pour accorder la religion chrétienne et la culture païenne. Position fortement soutenue par clément d'Alexandrie, alors qu'Origène et Eusèbe de Césarée restèrent plus prudents. Grégoire de Nazianz et Saint Augustin la critiquèrent âprement et ce fut justement la position de ce dernier qui s'imposa et qui influença profondément et largement la pensée du Moyen Âge. En revanche, le comparatisme sera l'apanage de la Renaissance (Marsile Ficin, Boccace, Bacon, Comes, Agostino Steuco, Livius Galantes, Mornai), continuera à se répandre à mesure que la méthode des érudits fera des progrès, réaffirmera et renforcera le diffusionnisme (platoniciens de Cudworth) et la thèse du plagiat sur base «philologique» (Selden, Gérard Vossius, Samuel Bochart, Daniel Heinsius, Athanase Kircher). Persuadé de la nécessité et de la possibilité d'accorder vérité chrétienne et fable païenne, continuateur de la pensée de Bochart poussée à l'extrême «évhémerisme supérieur», p. 44, Dupront), Pierre-Daniel Huet joue un rôle de premier plan comme mythologue, à son époque et, de façon plus ou moins évidente, tout au long du Siècle des Lumières. Ses continuateurs furent le père Dominique de Colonia, Guillaume de Lavur, les frères Fourmont, son contestateur le plus fervent Bossuet. Dans le but d'accorder raison et foi (qui demeure souveraine), intelligence et autorité, Huet interprète la fable comme «figure de vérité» (Saint Augustin) que les philosophes utilisent à notre avantage. Selon Huet, le goût pour l'affabulation est inné chez tout esprit humain. En s'appuyant sur des preuves historiques et étymologiques, il établit de nets parallélismes entre dogmes chrétiens et polythéisme, entre morale chrétienne et morale païenne, entre révélation chrétienne, révélation biblique, révélation naturelle (ce qui n'est pas sans danger pour le christianisme). C'est l'apothéose de comparatisme biblique et de la lecture allégorique. Un succès favorisé par d'étroits liens avec la physiologie (père Thomassin, père Le Bossu) qui permit de revendiquer la valeur littéraire et pédagogique de la fable.

4 Toutefois, l'accord entre vérités chrétiennes et fables païennes est bientôt contesté lors de la Querelle des Anciens et des Modernes et de la Querelle d'Homère entre La Motte et Madame Dacier (deuxième partie, «La fable laïcisée: la Querelle des Anciens et des Modernes»); controverses portant sur les contenus religieux et historiques, le style, le rapport merveilleux-vraisemblable, mais qui arrivèrent à un accord sur base historique (les Modernes ne niaient pas le caractère de source historique de l'lliade, ils 
prétendaient simplement soutenir la supériorité des temps modernes) et artistique (la fable n'appartient plus au poème épique mais elle se rapproche des genres littéraires nouveaux - notamment de l'opéra - capables de réaliser un équilibre entre merveilleux et chrétien). On entrevoit déjà le changement de perspective dont il est question dans les pages suivantes (troisième partie, «De la théologie à la chronologie: le temps des historiens»).

Les pensées de l'abbé Banier, Fréret, Fourmont, Guillaume de Lavaur, Guérin de Rocher, Newton, Cumberland, Dupin soulignent l'association de la fable et de l'histoire, de la philosophie et de la théologie, et réaffirment avec décision la valeur du comparatisme et de l'évhémerisme (Jean Leclerc). Julie Boch remarque qu'en général les auteurs du début du XVIII ${ }^{\mathrm{e}}$ abordent la réflexion sur la fable de façon similaire (méthode rationnelle), selon des points de départ communs (évhémerisme, double religion, consensus universel) et avec la même fin (objectivité), mais que chacun développe sa propre réflexion de façon personnelle et atteint à une théorisation et à une pensée très personnelle. C'est le cas des érudits protestants (Binet, Basnage, Jurieu), des érudits catholiques (abbé Houtteville, Dom Calmet, Rollin) et d'une voix singulière: celle de Fréret qui joint méthode cartésienne et érudition traditionnelle. La réflexion est passée des textes sacrés à l'histoire de l'esprit humain. Étape significative où s'insère parfaitement la personnalité de Bayle (quatrième partie, «La fable entre pessimisme calviniste et scepticisme rationaliste: Pierre Bayle»), penseur représentatif à la fois du comparatisme du siècle classique et de la nouvelle critique du XVIII ${ }^{e}$ siècle, non sans contradictions et complexités, qui concilie pessimisme calviniste et scepticisme rationaliste. Si d'un côté on condamne l'idolâtrie, la superstition, l'astrologie, les poètes antiques et, surtout, la faiblesse de l'esprit humain, si on affirme la supériorité de l'athéisme; de l'autre, on assimile cultes païens et christianisme (tombés exactement dans les mêmes erreurs), on admire certains penseurs grecs et latins, et le caractère didactique des fables d'Ésope, en continuité avec la tradition érudite.

Véritable enquête sur le rôle des religions dans l'histoire humaine, le chemin entrepris par Bayle est développé par Fontenelle (les fables ne sont que «l'histoire des erreurs de l'esprit humain», p. 413) et par les rationalistes sceptiques, dont les orientations sont analysées, avec les théories des déistes, dans la cinquième partie «Vers l'anthropologie: la fable dans l'histoire de l'esprit humain»). Ici, l'attention de Julie Boch est focalisée surtout sur l'affirmation de l'idée d'un monothéisme originel, antérieur à tout culte, dégradé par le paganisme et par le christianisme, idée formulée à partir d'une analogie établie entre la barbarie des peuples sauvages extra-européens et le paganisme de l'antiquité (le père Bouvet, le père de Prémare, Noël Alexandre, La Créquinière, Ramsay, le père Pezron, Dom Jacques Martin, Lafitau). La critique de la faiblesse de l'esprit humain et surtout des impostures des prêtres s'accentue dans le souci de chercher les origines de la religion et de son lien avec l'organisation sociale de tout peuple, l'esprit humain étant susceptible des mêmes constructions mentales dans tous les lieux et en tous les temps. Selon Julie Boch, Fontenelle a essentiellement le mérite d'avoir défini une mentalité primitive, d'avoir relevé l'existence d'une nature humaine universelle, d'avoir compris le rôle de la psychologie, d'avoir utilisé des techniques comparatives, une perspective historique, un style brillant refusant l'érudition (ce qui en fait le penseur le plus représentatif de la critique rationnelle des Lumières). Il réserve à la réflexion sur la mythologie une place considérable dans toute son œuvre: dans l'Histoire des oracles et De l'origine des fables, où il attaque âprement les superstitions, tout en faisant, néanmoins du polythéisme une phase primitive de la religion, éliminée peu à 
peu par la raison. Ses spéculations furent les sources d'autres analyses qui se concentrèrent sur la description des croyances primitives et qui mirent en évidence une tendance encore précédente au polythéisme: le fétichisme (de Brosses); elles furent aussi le tremplin des études des langues comme réservoirs inestimables de données sur les origines de l'humanité (Turgot, Pluche, Condillac). Vers le milieu du siècle, l'intérêt pour les origines de l'humanité est donc très vif et conduit non seulement aux tentatives d'expliquer la nature et la place de la religion dans la société contemporaine, mais à un examen de la portée politique de la fable. Dans le Contrat social, Rousseau veut discerner le lien entre la société antique et le culte païen, et théorise l'existence d'une théocratie primitive précédant la monarchie. Ces opinions influencèrent profondément la pensée historique sur la fable à venir, y compris celle de Voltaire qui s'est intéressé à la question du point de vue esthétique et poétique, mais aussi historique et déiste (Essai sur la poésie épique, Dictionnaire philosophique, Philosophie de l'histoire par feu l'abbé Bazin). Voltaire, le dernier penseur pris en considération par Julie Boch, soutient que les fables précèdent l'histoire et critique Bochart, Huet, Houtteville, Pluche, Jurieu avec l'ironie habituelle. Il ne met pas en cause l'authenticité esthétique, mais il conteste la valeur historique et religieuse de la fable. Tolérant envers l'idolâtrie en tant que forme de religion capable d'établir ou de préserver l'ordre social, partisan de la permanence historique de certains éléments chez tous les peuples (ce qui n'empêche pourtant pas les diverses évolutions), Voltaire admire Bayle sans être son disciple et se pose à michemin entre les Anciens et les Modernes.

Du terrain de la religion et de la poésie, on est passé, à travers le domaine de l'histoire et de l'esthétique, au champ de l'anthropologie. Le processus de «laïcisation progressive [et d'autonomie progressive] de la fable», malgré la persistance de certains préjugés, est parvenu à son bout et à son but. Dieux désenchantés, donc. Désenchantés par le christianisme, par l'histoire et la science, mais surtout par la raison, seul oracle et seule souveraine du Siècle des Lumières. 